\title{
ARQUIVOS
}

\section{AS FONTES PRIMÁRIAS DO MUNICÍPIO DE ALVINLÂNDIA.}

\author{
FRANCISCO NIVALDO DE BAPTISTA \\ Licenciado em História pela Faculdade de Filosofia, \\ Clências e Letras de Marilia (SP.).
}

Para elaboração do presente trabalho contamos com a colaboração das seguintes entidades:
a). - Prefeitura Municipal de Alvinlândia.
b). - Cartório do Registro Civil e Tabelionato de Alvinlândia.
c). - Câmara Municipal de Alvinlândia.
d). - Autoridudes Religiosas.
e). - Autoridades Escolares.
f). - Textos Legais Insertos nos Diários Oficiais Do Estado de São Paulo.

Alvinlândia, cidade do Estado de São Paulo, localiza-se a 22:23' (vinte e dois graus e vinte e três minutos) de latitude sul e a $49^{\circ} .48^{\prime}$ (quarenta e nove graus e quarenta e oito minutos) de longitude oeste de Greenwich.

A altitude do Município é seiscentos e sessenta e oito metros e a área municipal é $89 \mathrm{~km}^{2}$ (oitenta e nove quilômetros quadrados).

No dia 8 de agôsto de 1934 foi criado o povoado de Vila Couto, primitivo nome de Alvinlândia. Foram seus fundadores os seguintes senhores: Dr. José Bonifácio do Couto. João Manzano e Horácio Couto, sendo que o primeiro foi o mais importante, pois o povoado teve o seu nome até a época de sua elevação a Distrito a 13 de junho de 1953, quando ficou sendo conhecido por Distrito de Alvinlândia.

Antes de continuarmos com a História do município devemos dizer que o Dr. José Bonifácio do Couto muito batalhou por Vila Couto. Era dentista, sendo natural de Douradinho, Estado de Minas Gerais. Faleceu a 24 de julho de 1947, em Vila Couto, sendo enterrado no cemitério de Lupércio.

Como já dissemus acima Vila Couto tornou-se Alvinlândia a partir de sua elevação a distrito (13 de junho de 1953): o atual 
nome surgiu quando os deputados Cunha Bueno, Castro Carvalho e Joviano Alvim, membros da Comissão que opinava sôbre a criação de novos distritos, resolveram prestar uma homenagem ao pai do último membro da Comissão, ou seja, Joviano Alvim

Alvinlândia tornou-se município independente de Garça pela lei $\mathrm{n}^{\circ} 5285$ de $18 \mathrm{de}$ fevereiro de 1959 , publicada no Diário Oficial do Estado de São Paulo no dia 19 de fevereiro. Por fôrça dêsse diploma legal, Alvinlândia teve nove vereadores (1).

Os limites municipais de Alvinlândia foram também estabelecidos pela mesma lei: municípios de Lupércio, Garça, Gália, Ubirajara e São Pedro do Turvo (2). Conhecemos a região e sabemos que Lupércio fica a Oeste de Alvinlândia; São Pedro do Turvo fica ao Sul; Garça ao Norte de Alvinlândia; Gália a Nordeste e finalmente Ubirajara a Leste (3).

A instalação do Município de Alvinlândia ocorreu no dia $1^{\text {9 }}$ de janeiro de 1960, quando o Dr. Plínio Novaes de Andrade, Meretíssimo Juiz de Direito de Garça empossou os vereadores. Foram membros da primeira Câmara Municipal de Alvinlândia os seguintes senhores: Aydes Wanderley Belintani, Antônio Aparecido, Daniel Guarido, Estevam Leopoldino de Miranda, José Soares, João Pereira da Silva, José Natalino, Joaquim Ferreira de Assis e Vicente Manzano, sendo que o primeiro foi empossado posteriormente pela Câmara Municipal por não ter apresentado prova de quitação com o serviço militar por ocasião da instalação do Município (4).

Nesta mesma sessão foi eleita a Mesa que dirigiria os trabalhos legislativos do Município. Foram eleitos os seguintes vereadores:

a). - Presidente: Vicente Manzano, com sete votos.

b). - Vice-Presidente: Daniel Guar'do, com sete votos.

c). - Primeiro-Secretário: Antonio Aparecido, com sete votos.

d). - Segundo-Secretário: José Soares, com sete votos.

A sessão de instalação da Câmara Municipal de Alvinlândia foi presidida pelo Sr. Sebastião Manzano, que tomou posse no dia $1^{\circ}$ de janeiro de 1960. Seu mandato durou até o dia 31 de dezembro de 1963. Para o período seguinte foi eleito o Sr. José Maia Guimarães, governando o município de 10 de janeiro de 1964 a 31 de janeiro de 1969 (5).

\footnotetext{
(1). - Vide, in fine, Ata da Instalação do Município de Alvinlândia.

(2). - Vide, in fine, o trecho da lei que traz os limites do Municíplo.

(3). - Em nosso trabalho "Fontes Primárias de Lupércio" falamos que Alvinlândia fícava a Leste de Lupércio. Em conclusão, Lupércio fica a oeste do referido município: Sāo Pedro do Turvo também limita-se ao sul com Lupércio.

(4). - Vide a Ata da Câmara Municipal, in fine. O referido documento também traz os nomes dos componentes da Mesa da Câmara Municipal.

(5) . - o manc'ato to Sr. José da Maia Guimaráes fol prorrogato como os de outros prefeitos municipais do país pelo Sr. Presidente da República.
} 
O Sr. Juracy Arlindo Dias, eleito terceiro mandatário de Alvinlândia, tomou posse no dia $1^{\text {o }}$ de fevereiro de 1969.

Veremos agora as principais fontes primárias do Município de Alvinlândia:

\section{I. - CAMMARA MUNICIPAL.}

Foi instalada, como já dissemos, a $1^{0}$ de janeiro de 1960 . Estamos já na terceira legislatura. Os principais livros existentes são os seguintes:

a). - Livros de Presença.

São dois os livros de presença dos Senhores Vereadores. O primeiro livro traz o têrmo de abertura e rubrica do Sr. Vicente Manzano, sendo encerrado pelo Sr. Sebastião Manzano .Esse livro possui cem (100) fôlhas, contendo cento e noventa e oito sessões registradas. O segundo livro traz o têrmo de abertura e a rubrica feitos pelo Sr. Sebastião Manzano. Não foi ainda encerrado. Possui cem (100) fôlhas.

b). - Livros de Atas.

São dois os livros de Atas.

19). - Livro de Ata no 1: Contém 200 (duzentas) fôlhas, contendo 164 (cento e sessenta e quatro) atas. O têrmo de abertura e a rubrica foram feitos pelo Sr. Vicente Manzano, tendo o têrmo de encerramento sido assinado pelo Sr. Sebastião Manzano.

29). - Livro de Ata $n^{o}$ 2: Contém duzentas (200) páginas, não estando ainda encerrado. $\mathrm{O} \mathrm{Sr}$. Sebastião Manzano rubricou-o e assinou o têrmo de abertura.

c). - Livro de Comissóes.

São quatro. Servem para o registro dos trabalhos das Comissões especializadas da Câmara. O primeiro foi aberto, encerrado e rubr:cado pelo Sr. José Rondival Guarido; O segundo pelo Sr. Vicente Manzano; o terceiro pelo Sr. Gerônimo Carlos Soares; finalmente o quarto pelo Sr. Orozimbo Simões Fontes.

CARTORIO DO REGISTRO CIVIL E TABELIONATO DE ALVINLANDIA .

Alvinlândia tornou-se Distrito a 13 de junho de 1953. O Cartório de Alvinlândia tem como Oficial do Registro Civil o Sr. José Maia Guimarães. 
O Cartória acha-se instalado à Avenida Dr. Couto Jr. n 565 .

Faremos agora a relação dos livros existentes no mencionado Cartório:

a). - Livros de Nascimentos: todos os livros de registros de Nascimentos têm a sigla $A$, seguido do número do livro. Todos os livros foram autenticados pelo Meretíssimo Juiz de Garça, pois Alvinlândia pertença a aludida Comarca.

19). - Livro A-1; foi autenticado no dia 13 de junho de 1953. A assinatura é ilegível. O primeiro registro civil lavrado no Cartório foi o de Porcina Maria de Jesus, nascida a 13 de junho de 1952; filha do Sr. Benedito Siqueira Martins e de $D^{a}$ Vespertina Dias Martins.

29). - Livro A-2: autenticado no dia 26 de setembro de 1956. Pela informação do Cartório a assinatura do Juiz é ilegível. No entanto temos o nome do Juiz de direito de Garça na ocasião: é o Dr. Otávio Egydio Pagliero. Obtivemos êsse nome quando fizemos o nosso trabalho sôbre Fontes Primárias de Lupércio. Tanto Lupércio como Alvinlândia estão na Comarca de Garça (6).

39). - Livro A-3: O presente livro foi autenticado no dia 5 de fevereiro de 1960. A informação dá-nos como ilegível o nome do magistrado que fêz essa autenticação. Convém dizer que o Dr. Plínio Novaes de Andrade foi o magistrado garcense que instalou o $\mathrm{Mu}-$ nicípio de Alvinlândia no dia $1^{\text {19 }}$ de janeiro de 1960. O livro de nascimento $A-13$, de Lupércio, foi autenticado pelo referido magistrado no dia 26 de abril de 1960 . Logo, o livro $A-3$ de Alvinlândia foi aberto pelo Dr. Plínio (7) .

49). - Livro A-4: Foi autenticado no dia 6 de novembro de 1963 pelo Dr. Francisco Vieira de Moraes Barros. Não está ainda encerrado.

b). - Livros de Casamentos: O Cartório de Alvinlândia tem três livros de Casamentos. Todos êles têm a sigla B seguida do número do mesmo.

19). - Livro B-1: autenticado no dia 13 de junho de 1953. O nome do Juiz é ilegível. O primeiro casamento foi realizado perante o Meretíssimo Juiz de Casamento Sr. Benedito Garcia Lima, no dia 27 de junho de 1953 . Os nubentes dêsse ato foram os senho-

\footnotetext{
(6) . - O livro A-12, de I.upércio, fol autenticado por êsse magistrado no dia 17 de outubro de 1956. Fol, portanto, êle que fêz o de Alvinlânaia.

(7). - Vide o nosso trabalho "Fontes Primárias de Lupércio".
} 
res José Inácio Bernardino e Olinda Alves de Souza. A contraente passou a assinar Olinda Alves Bernardino.

$\left.2^{\circ}\right)$. - Livro B-2: Autenticado no dia 2 de janeiro de 1959. A informação que temos é que a assinatura do Juiz é ilegível. No entanto, o livro $B-8$ que traz os casamentos de Lupércio foi autenticado no dia 27 de outubro de 1959 pelo Dr. Plínio Novaes de Andrade: isto leva-nos a crer que o referido magistrado autenticou o livro $B-2$ de Alvinlândia (8).

39). - Livro B-3: Foi autenticado pelo Juiz de Garça no dia 7 de julho de 1964. Pela informação sua assinatura é ilegível. O livro $B-9$ de Lupércio, autenticado a 03 de novembro de 1964, traz a assinatura do Dr. Francisco Vieira de Moraes Barros. Aliás o livro $A-4$ de Alvinlândia, aberto a 06 de novembro de 1963 traz a assinatura do referido magistrado (9).

c) . - Livros de Obitos: Levam a sigla $C$ acompanhada do número do livro. O Cartório de Alvinlândia possui sòmente um livro de óbitos.

19). - Livro C-1: autenticado no dia 13 de junho de 1953 . A assinatura do Juiz é ilegível. O primeiro assento feito foi de um nati-morto, do sexo masculino, ocorrido no dia 19 de junho de 1953 na Fazenda Torrão de Ouro, no distrito de Alvinlândia.

d). - Livros de Editais de Proclamas: Têm a sigla $D$, acompanhada do número do livro. $\mathrm{O}$ mencionado cartório possui sòmente um livro de Editais de Proclamas que ainda não está encerrado.

19). - Livro D-1: autenticado no dia 13 de junho de 1953, pelo MM. Juiz da Comarca de Garça, cuja assinatura é ilegível.

Além dêsses livros citados o Cartório possui 8 (oito) livros de escrituras; 4 (quatro) livros de procurações e 2 (dois) livros de feitos. Não daremos aqui as datas de aberturas de cada um porque não as possuímos em mãos.

Achamos que os cartórios são úteis para as fontes primárias porque nos permitem fazer estudos sôbre a natalidade e, por outro lado, sôbre a mortalidade do Município. Os cartórios civis dos $\mathrm{Mu}$ nicípios que não sejam sede de Comarca, funcionam como Tabelionatos permitindo estudos sôbre transações imobiliárias.

(8) . - Vide nosso Trabalho sôbre "Fontes Primárias de Lupérclo".

(9). - Idem. 


\section{CONGREGAÇÃO CRISTÃ NO BRASIL:}

A Congregação Cristã no Brasil de Alvinlândia teve abertura no ano de 1954. Não possui $A$ ta por não ser desmembrada, não possuindo, portanto, Conselho Fiscal. O número de fiéis é, aproximadamente, setenta.

A Igreja funciona com três procuradores, na parte material; um cooperador, na parte espiritual. O Sr. Arthur Marques Filho é o cooperador; os procuradores são os seguintes senhores: Albino Natalino (registrado), Eduardo Bento dos Santos e João Pedro da Silva (ambọ não são registrados) .

\section{* * \\ IGREJA EVANGELICA ASSEMBLEIA DE DEUS.}

A Igreja Evangélica Assembléia de Deus de Alvinlândia poss'i 32 fiéis (10). Não tem personalidade jurídica, estando ligada à Igreja de Lupércio. Esta congrega os fiéis de Lupércio, Santa Terezinha (11), Ocauçú, Alvinlândia e Ubirajara.

O Reverendo Apim da Silva Neves atende não só os fiéis de Lupércio como também os das outras comunidades ligadas à Igreja de Lupércio.

Encontramos o número de fiéis no Livro do Ról de Membros que se encontra na Igreja de Lupércio. O referido livro possui quatrocẹntas páginas. Além dêsse livro encontramos os seguintes:

a). - Livro de Atas: aberto a 26 de abril de 1966, com cem (100) fôlhas, por Francisco Ferreira Rodrigues.

b) . - Livro de Conta Corrente: com duzentas (200) fôlhas; aberto no mês de julho de 1967. E' o livro de Caixa (12).

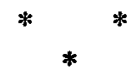

\section{IGREJA MATRIZ DE SANTO ANTONIO:}

E' dedicada a Santo Antônio, padroeiro de Alvinlândia. A cidade tornou-se Distrito no dia 13 de junho de 1953.

\footnotetext{
(10). - Vide nosso trabalho sôbre "Fontes Primárias de Lupércio. Os fatos dêste trabalho foram baseados no trabalho de Lupércio.

(11). - Santa Terezinha é um patrimônio de Luperclo.

(12) . - Vide nosso trabalho "Fontes Primárias de Lupércio".
} 
A Igreja está dentro da Paróquia de Santo Inácio, de Lupércio, sendo todos os fatos da localidade registrados em livros da referida paróquia. Alvinlândia está, portanto, dentro da diocese de Assis cujo bispo é D. José Lázaro das Neves.

O vigário da Paróquia de Santo Inácio é o Padre Mário Rossetti, que atualmente está na Itália. Está sendo substituído pelo Padre Ilson José Frossard.

A bênção das tôrres do referido templo foi no dia 25 de junho de 1955, sendo dada por D. José Lázaro das Neves. À tarde dêsse mesmo dia uma comissão de Ubirajara visitou o ilustre prelado e pediu-lhe que a Capela de Ubirajara passasse a pertencer, até a vinda de um nôvo vigário, à paróquia de Santo Inácio. Sua Exa Revma atendeu ao pedido da comissão nomeando o Padre Júlio Vittori, primeiro vigário de Lupércio, como coadjutor do Padre Marcílio Genani, vigário de São Pedro do Turvo, para a Capela de Ubirajara. A referida comissão foi recebida na Casa Paroquial de Lupércio por D. José Lázaro das Neves. A nomeação do Padre Júlio para o nôvo cargo foi datada no dia 19 de outubro de 1955 (13). O estilo da Igreja de Santo Antônio é colonial.

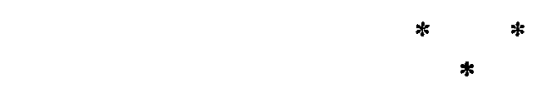

GRUPO ESCOLAR JOSE BONIFACIO DO COUTO.

O Grupo citado atende às crianças da cidade de Alvinlândia. Possui seis classes de aulas. O referido estabelecimento de ensino tem o nome do Dr. José Bonifácio do Couto, fundador de Alvinlândia.

O referido estabelecimento Situa-se à Rua Major Couto s/número. O seu telefone é 10 .

Não temos em mãos a data da criação do referido estabelecimento nem a data de instalação. Não possuimos também o número da lei que deu a atual denominação apesar de termos pedido, por escrito, ao Diretor do referido Grupo. Para a elaboração do presente trabalho solicitamos informações oficiais.

Há doze escolas isoladas na Zona Rural de Alvinlândia a fim de atenderem as crianças que não podem ir estudar na cidade.

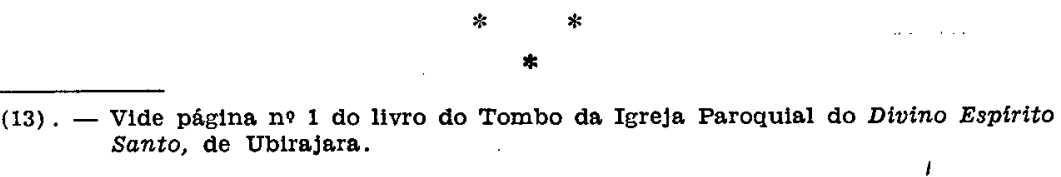




\section{GINASIO ESTADUAL DE ALVINLÂNDIA.}

Localiza-se à Avenida Dr. Couto Júnior n⿳os 234 e 248 (14). O seu telefone é 17 (15).

O Prof. João Carlos Gonçalves é responsável pelo expediente interno do estabelecimento (16) .

O Ginásio Estadual de Alvinlândia foi criado pela Lei número 9.222, promulgada pelo $\mathrm{Dr}$. Adhemar Pereira de Barros, no dia 4 de janeiro de 1966, conforme o texto que segue:

LEI N 9.222, DE 4 DE JANEIRO DE 1966

Dispõe sôbre a criação de Ginásio Estadual em Alvilândia

O GOVERNADOR DO ESTADO DE SAO PAULO:

Faço saber que a Assembléia Legislativa decreta e eu promulgo a seguinte lei:

Artigo $1^{\circ}$ - E' criado um Ginásiơ Estadual em Alvinlândia.

Artigo $2^{\circ}-$ A lei orçamentária do exercício em que se der a instalação do estabelecimento de ensino ora criado consignará dotações necessárias a ocorrer às respectivas despesas.

Artigo $3^{\circ}$ - Esta lei entrará em vigor na data de sua publicação.

Palácio dos Bandeirantes, aos 4 de janeiro de 1966.

ADHEMAR PEREIRA DE BARROS

José Carlos de Ataliba Nogueira

Publicada na Diretoria Geral da Secretaria de Estado dos Negócios do Govêrno, aos 4 de janeiro de 1966.

Miguel Sansigolo, Diretor Geral, Substituto.

O Ginásio Estadual foi instalado no dia 06 de maio de 1966 pelo Professor Dr. João Nunes Miranda, DD. Inspetor Regional do Ensino Secundário e Normal de Marília (17). O funcionamento foi a partir da data citada.

Apresentaremos agora a relação dos Livros Existentes na Secretaria do Ginásio Estadual de Alvinlândia. Todos êles foram autenticados pelo Prof. João Carlos Gonçalves: :

$$
\begin{aligned}
& \left.1^{\circ}\right) \text {. - Têrmo de Visita } \\
& \left.2^{\circ}\right) \text {. - Material Existente Nas Dependências do Es- } \\
& \text { tabelecimento } \\
& \left.3^{\circ}\right) \text {. - Inscriçốes aos Exames de Admissão } \\
& \left.4^{9}\right) \text {. - Exames Biométricos } \\
& \left.4^{\circ}\right) \text {. - Inscrições de Candidatos à Regência de Aulas } \\
& \text { Excedentes } \\
& 50 \text { Fôlhas } \\
& 50 \text { Fôlhas } \\
& 50 \text { Fôlhas } \\
& 50 \text { Fôlhas } \\
& \left.6^{\circ}\right) \text {. - Posse e Exercício de Funcionários }
\end{aligned}
$$

(14). - Informação do Sr. Prof. João Carlos Gonçalves.

(15). - Vide Guia dos Telefones da Regional Sul Paulista 1969; pág. 16.

(16). - Informaçêo do Sr. Diretor do Gináslo Estadual de Alvinlândia.

(17) . - Marilia é a sede da 16a. Inspetoria Regional do Ensino Secundário e Normal. 


$\begin{array}{lr}-459- \\ \left.7^{\circ}\right) .- \text { Matriculas de Alunos ao Curso Ginasial } & 100 \text { Fôlhas } \\ \left.8^{\circ}\right) . \text { - Ocorrências no Estabelecimento } & 100 \text { Fôlhas } \\ \left.9^{\circ}\right) .- \text { Reunião do Conselho de Classe } & 50 \text { Fôlhas } \\ \left.10^{\circ}\right) .- \text { Reunião Pedagógica } & 50 \text { Fôlhas } \\ \left.11^{\circ}\right) .- \text { Ata dos Exames do Estabelecimento } & 100 \text { Fôlhas } \\ \left.12^{\circ}\right) .- \text { Registro de Empregados Contratados pela } & \\ & 50 \text { Fôlhas } \\ \left.13^{\circ}\right) . \text { C.L.L. Ponto do Pessoal Administrativo } & 200 \text { Fôlhas } \\ \left.14^{\circ}\right) .- \text { Ponto do Pessoal Docente (18) } & 200 \text { Fôlhas }\end{array}$

Estas são as unidades de ensino no município de Alvinlândia. Os alunos que terminam a quarta série ginasial no referido estabelecimento de ensino dirigem-se a Lupércio para cursarem o Colegial na Escola Normal Municipal de Lupércio.

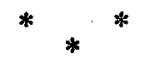

MEIOS DE TRANSPORTES.

a). - Rodoviário:

Há duas emprêsas que servem o Município:

19). - Viação Ourinhense Ltda.: Faz a linha Marilia-Santa Cruz do Rio Pardo, pasando por Alvinlândia.

.29). - Sociedade de Transporte Garça Ltda.: Faz a linha Garça-Ocauçú também pasando pela localidade citada.

Estes são os únicos meios de transportes do Município pois Alvinlândia não tem ligação ferroviária com outras cidades. Qualquer munícipe que deseja ir a São Paulo deve dirigir-se até Garça ou Marília para tomar o trem da Companhia Paulista de Estrada de Ferro; ônibus do Expresso de Prata ou outras emprêsas.

\section{Assistência Médico-Sanitária.}

Quanto à Assistência Médico-Sanitária, Alvinlândia é assistida pelos seguintes elementos:

a). - Pôsto de Assistência Médico-Sanitária Estadual.

Tem a sigla $P . A . M . S$. . E' dirigido pelo Dr. Galeno Americáno do Brasil, que também atende ao pôsto de igual nome em Lupércio (19) . Possui uma ambulância que atende à Saude Pública .

\footnotetext{
(18). - Informação prestada pelo Professor João Carlos Gonçalves, diretor do Gináslo Estadual de Alvinlândia.

(19) . - Vide o nosso trabalho sôbre "Fontes Primárias de Lupércio". Lecionamos em Lupércio e o Dr. Galeno atende à comunidade luperciana.
} 
b). - Um Socôrro Farmacêutico.

c). - Dois Gabinetes Dentários. lista de Fôrça e Luz".

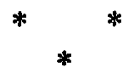

\begin{abstract}
ENERGIA ELETRICA:
O município é servido por energia elétrica da "Companhia Pau-
\end{abstract}

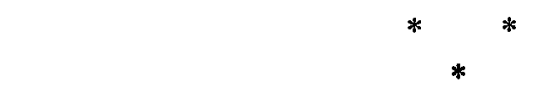

AGENCIAS BANCÁRIAS:

Alvinlândia não possui agências bancárias. Possui uma Agência da Caixa Econômica do Estado de São Paulo anexa à Coletoria Estadual.

\title{
$*$
$*$
DELEGACIA DA SEGURANÇA PUBLICA .
}

Conta com uma delegacia de Polícia.

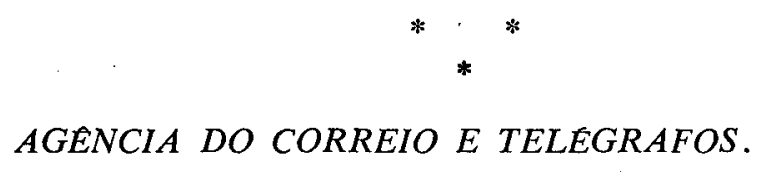

Alvinlândia tem uma agência de Correio e Telégrafos para atender aos munícipes.

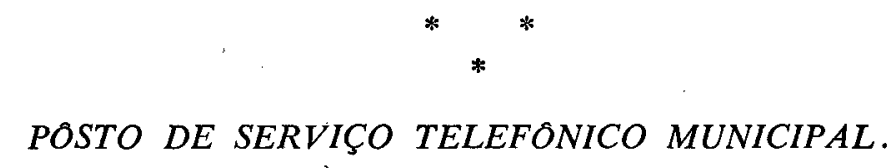

Alvinlândia possui um Pôsto de Serviço Telefônico Municipal que atende à comunidade alvinlandense. $\mathrm{O}$ telefone coloca os munícipes em contacto com outras cidades paulistas e do país. 
COMERCIO.

Há dezessete casas comerciais para atender à população.

\section{PREFEITURA MUNICIPAL.}

Foi instalada a $1^{\circ}$ de janeiro de 1960 . Até essa data Alvinlândia pertencia ao município de Garça como Vila Couto e depois como Distrito de Alvinlândia.

A Prefeitura Municipal possui as Secções de: Contadoria, Tesouraria, Secretaria, Setor de Fiscalização, Setor Pessoal e outros inerentes à Administração Pública Municipal .

A Prefeitura possui também u'a Motoniveladora e demais conduções para a conservação de rodovias. Há também um poço semi-artesiano que serve a população.

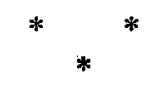

\section{CLIMA .}

O clima de Alvinlândia é quente com inverno sêco. A média compensada é de $21^{\circ} \mathrm{C}$.

BRASÃO DE ARMAS:

O Município não possui brasão de armas. Pode-e notar nos documentos da Prefeitura Municipal como na da Câmara que é o Brasão do Estado de São Paulo que aparece.

\section{ATIVIDADES ECONOMICAS.}

O café e o gadio são as atividades econômicas básicas do Município. Os outros produtos de Alvinlândia são: arroz, milho, feijão, amendoim, algodão, etc. 


\section{APENDICES.}

\section{LIMITES DO MUNICIPIO DE ALVINLANDDIA PUBLICADOS NO DIARIO OFICIAL DO ESTADO DE SÃO PAULO NO DIA 19 DE FEVEREIRO DE 1959.}

\section{MUNICIPIO DE ALVINLÂNDIA}

(Criado em 1953).

\section{a). - DIVISAS MUNICIPAIS}

\section{1. - Com o Municipio de Lupércio.}

Começa no ribeirão Santo Inácio na foz do córrego Mombuca; sobe pelo ribeirão Santo Inácio até a foz do ribeirão Barra Grande; sobe por êste ribeirão até a foz do córrego Macaquinho; sobe, ainda, por êste córrego, até sua cabeceira setentrional; continua pelo contraforte fronteiro até o divisor Barra Grande - São João; prossegue por êste divisor até a cabeceira do córrego Santa Tereza, pelo qual desce até sua foz no Rio São João; sobe pelo rio São João até a foz do córrego Benedito Baiano, primeira água da margem esquerda, à montante da foz do córrego São Luís; sobe por essa ágưa até sua cabeceira, no espigão mestre São João - Alegre.

\section{2. - Com o Municipio de Garça.}

Começa no espigão mestre São João - Alegre, na cabeceira do córrego Benedito Baiano, primeira água da margem esquerda do rio São João à montante da foz do córrego São Luís; segue pelo espigão mestre entre as águas do rio São João, à direita, e as do ribeirão do Alegre, à esquerda, até a cabeceira do córrego da Égua ou Comprido.

\section{3. - Com o Municipio da Gália.}

Começa no espigão mestre São João - Alegre, na cabeceira do córrego da Égua ou Comprido, pelo qual desce até sua foz no rio São João.

\section{4. - Com o Municipio de Ubirajara.}

Começa no rio São João, na foz do córrego da Egua ou Comprido; segue pelo contraforte fronteiro até o divisor que separa as águas do córrego Jaú das da água do Barbosa; segue por êste divisor até o divisor entre o rio São João, à direita, e ribeirão Anhumas, a esquerda; prossegue por êste divisor até a cabeceira oriental do córrego do Dirígio, pelo qual desce até sua foz no ribeirão Anhumas; segue pelo contraforte fronteiro até o divisor Anhumas - Santo Inácio; segue por êste divisor até cruzar com o contraforte entre os córregos Barra Nova e Estiva.

\section{5. - Com o Municipio de Säo Pedro do Turvo.}

Começa no contraforte que deixa, a esquerda as águas do córrego Barra Nova e, à direita, as do córrego Estiva, no ponto de entrocamento com o divisor entre as águas dos ribeirões Santo Iná- 
cio e Anhumas; segue pelo contraforte até a cabeceira do córrego Mombuca, pelo qual desce até o rio Santo Inácio, onde tiveram inicio estas divisas.

NUMERO DE VEREADORES ESTABELECIDO PELA LEI $N^{\circ} 5285$ DE 18 DE FEVEREIRO DE 1959 - PUBLICADO NO DIARIO OFICIAL DO DIA SEGUINTE. (ART $14-$ LETRA C).

Artigo 14 - Aplicado o critério estabelecido pelo art. $2^{\circ}$ e seu

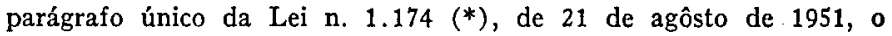
número de vereadores dos municípios criados por esta lei, é fixado, para a primeira legislatura, da seguinte forma:

a). -23 (vinte e três) para Osasco.

b). - 11 (onze) para Inúbia Paulista, Itapevi, Mairinque, Nova Odessa e Santa Albertina.

c). - 9 (nove) para Adolfo, Altair, Alvinlândia, Areiópolis, Arujá, Barbosa, Bom Jesus dos Perdões, Boracélia, Borboleta, Caieras, Cajamar, Cândido Rodrigues, Cassia dos Coqueiros, Catiguá, Cesário Lange, Colômbia, Diadema, Dolcinópolis, Embú, Floreal, Gabriel Monteiro, Guapuã, Guarani d'Oeste, Iacri, Itobi, Jaci, João Ramalho, Luis Antonio, Luibiânia, Mendonça, Meridiano, Mirassolândia, Mongaguá, Nova Guataporanga, Ocauçu, Palmeira d'Oeste, Pardinho, Peruibe, Pirapora do Bom Jesús, Populina, Pradópolis, Rafard, Roseira, Sagres, Sales, Salmorão, Sandovalina, Santa Lúcia.

\section{* * * \\ CAMMARA MUNICIPAL DE ALVINLÂNDIA. \\ Estado de São Paulo. \\ ATA DA SESSÃO ESPECIAL DE INSTALAÇÃO DA \\ CAMARA MUNICIPAL DE ALVINLANDIA.}

of. $N^{\circ} \ldots \ldots$

Ao primeiro dia do mês de janeiro do ano de mil novecentos e sessenta, no edifício destinado ao funcionamento da Câmara Municipal de Alvinlândia, compareceu o Exmo. Snr. Juiz de Direito da Comarca de Garça, Dr. Plinio Novaes de Andrade, para o fim especial de instalar o município de Alvinlândia assim como a sua Câmara Municipal, e, sob a sua presidência foram iniciados os trabalhos, de acôrdo com as disposições legais vigentes. Achavam-se presentes, além do $\mathbf{M}$. Juiz, os senhores Irso Imanioto, Prefeito $\mathrm{Mu}-$ nicipal de Lupércio, Manoel Joaquim Fernandes, Prof. José Porfírio e Manoel Galdino de Carvalho, vereadores eleitos à Câmara $\mathrm{Mu}$ nicipal de Garça, Tenente Candido Henrique de Campos, Delegado do Recrutamento, Ernesto Daun e Newton Romano Alves Costa, ve- 
readores, à Câmara Municipal de Lupércio, Dr. Rafael Paes de Barros, prefeito eleito de Gara, representado pelo Dr. Sebastião Guanaes Simões, e mais pessoas gradas. Procedida a abertura da sessão, o M. Juiz convidou a mim Jacy Fernandes, para secretariá-la, e em seguida foi feita a chamada dos Srs. Vereadores eleitos, verificando o M. Juiz a presença dos seguintes: Aydes Wanderley Belintani, Antonio Aparecido, Daniel Guarido, Estevam Leopoldino de Miranda, José Soares, João Pereira da Silva, José Natalino, Joaquim Ferreira de Assis e Vicente Manzano, os quais exibiram os seus diplomas que foram examinados. Deixou de tomar posse o vereador eleito Aydes Wanderley, por não ter apresentado prova de quitação com o serviço militar, ficando para ser empossado posteriormente perante a Câmara. Os demais apresentaram prova de quitação militar. A seguir o M. Juiz declarou empossada a Câmara Municipal de Alvinlândia. Em seguida convidou o vereador Antonio Aparecido para secretariar a sessão procedendo a seguir à eleição da mesa que dirigirá os trabalhos legislativos no corrente ano. Procedida a eleição segundo a Lei 2.550 constatou o seguinte resultado: Presidente: Vicente Manzano, com 7 votos; Vice-Presidente: Daniel Guarido, com 7 votos; $1^{\text {o }}$ Secretário: Antonio Aparecido, com 7 votos; $2^{\circ}$ Secretário: José Soares, com 7 votos. Ato contínuo o $\mathrm{M}$. Juiz anunciou o resultado da votação convidando o Presidente eleito a assumir a Presidência, o que foi feito sob salva de palmas. Antes, porém, o $M$. Juiz declarou que a votação foi feita por cédulas assinadas, abertas, as quais passarão a fazer parte do arquivo desta casa. Nada mais havendo, 'o $M$. Juiz deu por encerrada esta $1^{\text {a }}$ parte da sessão, mandando fôsse lavrada esta ata que foi feita por mim Jacy Fernandes, secretário que a subscreveu, e assinada pelos presentes: - (a. a) Dr. Plinio Novaes de Andrade - Vicente Manzano - Ilegível - Sebastião Afonso Lamunier - José Natalino - Joaquim Ferreira de Assis - João Pereira da Silva - Daniel Guarido - Estevam Leopoldino de Miranda - Aydes Wanderley Belintani - José Soares - Antonio Aparecido - Ilegível - Ernesto Daun - Ilegível - Ilegível - João Manzano - Manoel José Porfírio - Newton Romano Alves Costa - Sebastião Guanaes Simões (Representando o Sr. Rafael Paes de Barros e a Câmara Municipal de Garça) - Ary Tavares Boechat - Manoel Galdino Carvalho Ilegível - Ilegível - Matias Alves Negrão - Albino Croulin José Bosqueti - Maria José Caraco Manzano - Ilegível - José Rodrigues Negão - Porcim Antonio de Lima - Ivette Cardoso Manzano - Washington Miranda - Ruth S. S. Andrade - Moisés José Magalhães - Dagmarlene Arêdes Dias - Natinidade Arêdes Dias - Francisca Ruis Caraco - Caetano Zapata Filho - Regina Maria Manzano Belini - Waldemar Belini - José Carlos Cardoso Manzano - Therezinha Manzano - Maria Queiróz Ilegível - Vitória C. Queiróz. -

$$
\begin{gathered}
\text { " } E / P / A " \\
\text { VD-JR-FTL } \\
14-08-69 .
\end{gathered}
$$

